\title{
Mechanical Attributes of Uniaxial Compression for Calcium Carbonate Whisker Reinforced Oil Well Cement Pastes
}

\author{
Yuanyi Yang, ${ }^{1,2}$ Shun $\mathrm{Fu}^{3}$ and Xingkui $\mathrm{Li}^{2}$ \\ ${ }^{1}$ College of Materials and Chemistry \& Chemical Engineering, Chengdu University of Technology, Chengdu, China \\ ${ }^{2}$ Department of Materials Engineering, Sichuan College of Architectural Technology, Deyang, China \\ ${ }^{3}$ College of Administrative Science, Chengdu University of Technology, Chengdu, China \\ Correspondence should be addressed to Shun Fu; fs@cdut.edu.cn
}

Received 18 June 2017; Revised 11 August 2017; Accepted 6 September 2017; Published 23 November 2017

Academic Editor: Rishi Gupta

Copyright (c) 2017 Yuanyi Yang et al. This is an open access article distributed under the Creative Commons Attribution License, which permits unrestricted use, distribution, and reproduction in any medium, provided the original work is properly cited.

It is crucial for design and safety of the cementing sheath to develop better understanding of the $\mathrm{CaCO}_{3}$ whisker reinforced oil well cement pastes. The uniaxial compression curve, mechanical constitutive relation, and reinforcing mechanism of the $\mathrm{CaCO}_{3}$ whisker reinforced oil well cement pastes are studied in this script. The results indicate that the $\mathrm{CaCO}_{3}$ whisker under the $10 \%$ dosage could improve the tensile strength of the cement paste significantly. The peak stress, elasticity modulus, and the energy at different stages of the stress-strain curve of the $\mathrm{CaCO}_{3}$ whisker reinforced cement paste are reinforced with the increasing of $\mathrm{CaCO}_{3}$ whisker. Afterward, the constitutive model of stress-strain curve, the toughness index, and capability coefficients index of the $\mathrm{CaCO}_{3}$ whisker reinforced cement paste are established. A physical model of the interface layer is also established and the micromechanical reinforcement is related to the double film layer between the $\mathrm{CaCO}_{3}$ whisker and cement matrix which could be bonded with much more fastness to the cement surface. The development of this script provides new ways to analyze the toughening mechanism of $\mathrm{CaCO}_{3}$ whisker and establishes a correlation between basic material structure and the physical properties.

\section{Introduction}

With many advantages such as excellent mechanical properties, modest price, easy producing process, and natural compatibility with the cement, the application of inorganic crystal whiskers is developing rapidly in the industry. The application of inorganic crystal whiskers in the cement based composite not only is with high worth for academic research and good prospect of engineering employment but is also important for the energy conservation and sustainable development in the manufacture. The researches focused on the inorganic crystal whiskers reinforced cement pastes are gradually improved as a hotspot. Cao et al. $[1,2]$ have firstly explored the calcium carbonate whiskers in the cement based composite as reinforcing material, and the result of the study shows that the compressive strength, flexible strength, and tensile strength of the cement pastes with calcium carbonate whisker are increased. Cao et al. [3] have researched the cement pastes with hybrid fibers of calcium carbonate whisker and basalt fiber which displays that the hybrid effect with different kinds of fibers could arise in the cement pastes and the mechanical property of the cement pastes would be improved further than with just single fiber. Simultaneously, with the perfect performance of high strength, high elasticity modulus, excellent heat-resisting, and heat insulation, the calcium carbonate whisker as a kind of desired filling material could fit the requests of the cementing and geological engineering in petroleum industry well $[1,4]$. Li et al. [5, 6] have explored the workability of the cement slurry and the mechanical performance and the microstructure of the oil well cement pastes with hybrid fibers of calcium carbonate whisker and carbon fiber. The strengthening mechanism with hybrid fibers is elaborated as hybrid reinforcement. Ming et al. [7] have found that calcium carbonate whisker could not only reinforce mechanical performance of the oil well cement pastes but also develop the static gel strength conspicuously that could enhance the gas channeling prevention of the oil well cement slurry.

From the above, almost all the studies are focused on the traditional mechanical performances of cement pastes and 
TABle 1: Properties of $\mathrm{CaCO}_{3}$ whisker.

\begin{tabular}{|c|c|c|c|c|c|c|}
\hline Material & Density ratio & $\begin{array}{c}\text { Relative } \\
\text { molecular weight }\end{array}$ & Draw ratio & Appearance & Size & Origin \\
\hline $\begin{array}{l}\mathrm{CaCO}_{3} \\
\text { whisker }\end{array}$ & $2.8 \mathrm{~g} / \mathrm{cm}^{3}$ & 100.09 & $20-30$ & & $20-80 \mu \mathrm{m}$ & $\begin{array}{l}\text { China, Shandong } \\
\text { Runxing Chemical } \\
\text { Industry Co., Ltd. }\end{array}$ \\
\hline
\end{tabular}

TABLE 2: Mix proportions of cement pastes.

\begin{tabular}{|c|c|c|c|c|c|c|}
\hline $\begin{array}{l}\mathrm{CaCO}_{3} \\
\text { whisker } \\
\text { dosage } \\
\end{array}$ & $\begin{array}{c}\text { Cement } \\
\text { (g) }\end{array}$ & $\begin{array}{c}\text { Defoaming } \\
\text { agent } \\
(\mathrm{g})\end{array}$ & $\begin{array}{l}\text { Water } \\
\text { reducer } \\
(\mathrm{g})\end{array}$ & $\begin{array}{l}\text { Water } \\
(\mathrm{g})\end{array}$ & $\begin{array}{c}\mathrm{CaCO}_{3} \\
\text { whisker } \\
(\mathrm{g})\end{array}$ & $\begin{array}{c}\text { Water- } \\
\text { cement } \\
\text { ratio } \\
\end{array}$ \\
\hline 0 & 800 & 1 & 8 & 352 & 0 & 0.44 \\
\hline $3 \%$ & 776 & 1 & 8 & 352 & 24 & 0.44 \\
\hline $5 \%$ & 760 & 1 & 8 & 352 & 40 & 0.44 \\
\hline $8 \%$ & 736 & 1 & 16 & 352 & 64 & 0.44 \\
\hline $10 \%$ & 720 & 1 & 16 & 352 & 80 & 0.44 \\
\hline
\end{tabular}

workability of the cement slurry. Meanwhile, the constitutive relation is based on the mechanical properties of cement pastes and the macroscopic constitutive model of cement paste could be established through the experimental data as a kind of continuous state material. As a key basic property, the uniaxial compression of cement pastes is important to research of the bearing capacity and the deformability of cement sheath. And the stress-strain diagram is also a reflection of comprehensive capability of the cement material. The arising of the plastic deformation, producing and extending of the microcrack, peak strength, and the ultimate deformation of the cement pastes all appeared in the stress-strain diagram as the most important factors account for the compressive capacity and nonlinear process [8-11]. Nevertheless, the researches appearing in studies of the constitutive relation and stress-strain diagram of uniaxial compression focused on the $\mathrm{CaCO}_{3}$ whisker reinforced oil well cement pastes are quite insufficient.

The purpose of this study is to gain a better comprehending of the physical properties as well as the strengthening and toughening mechanism of the $\mathrm{CaCO}_{3}$ whisker reinforced oil well cement pastes. Establishing the constitutive relation between the $\mathrm{CaCO}_{3}$ whisker and oil well cement pastes, analyzing the stress-strain diagram, and calculating the physical model of interface layer are helpful for further research on the oil well cement based composite material. Therefore, the uniaxial compression curve, mechanical constitutive relation, and microreinforcing mechanism of the $\mathrm{CaCO}_{3}$ whisker reinforced oil well cement pastes are tested and discussed in this script to elaborate the fundamental physical effect of $\mathrm{CaCO}_{3}$ whisker reinforced oil well cement paste, which could lead to a better design and more safer cementing sheath, to achieve desirable toughing effects and improve wellbore integrity.

\section{Materials and Methods}

The materials applying in this script were cement ( $G$ high sulfur resistant oil well cement, Sichuan, China), $\mathrm{CaCO}_{3}$ whisker, water reducer (phenol and formaldehyde condensation polymer, Chengdu, China), defoaming agent (dibutyl phosphate, Chengdu, China), and pure water. The basic properties and chemical constituents of $\mathrm{CaCO}_{3}$ whisker were shown in Table 1, respectively.

The cement slurry of $\mathrm{CaCO}_{3}$ whisker was produced based on the Chinese standard "GB10238-2005 Oil Well Cement" and "GB/T19139-2012: The Application Performance and Test Methods of Oil-Well Cement." Thereafter, the mix design was divided into three steps which were elucidated as follows.

Step 1. The water reducer was mixed with the cement powder for $5 \mathrm{~min}$ by cement mortar mixer as predispersing powder.

Step 2. The $\mathrm{CaCO}_{3}$ whisker powder was mixed with the cement predispersing powder according to the quality fraction of the cement (as shown in Table 2) for $5 \mathrm{~min}$ before being agitated with water.

Step 3. All the mixed powder was transported to a high speed mixer for blending with water in 2 min and producing the cement slurry, whereby the mixing procedures were illustrated in Figure 1. 


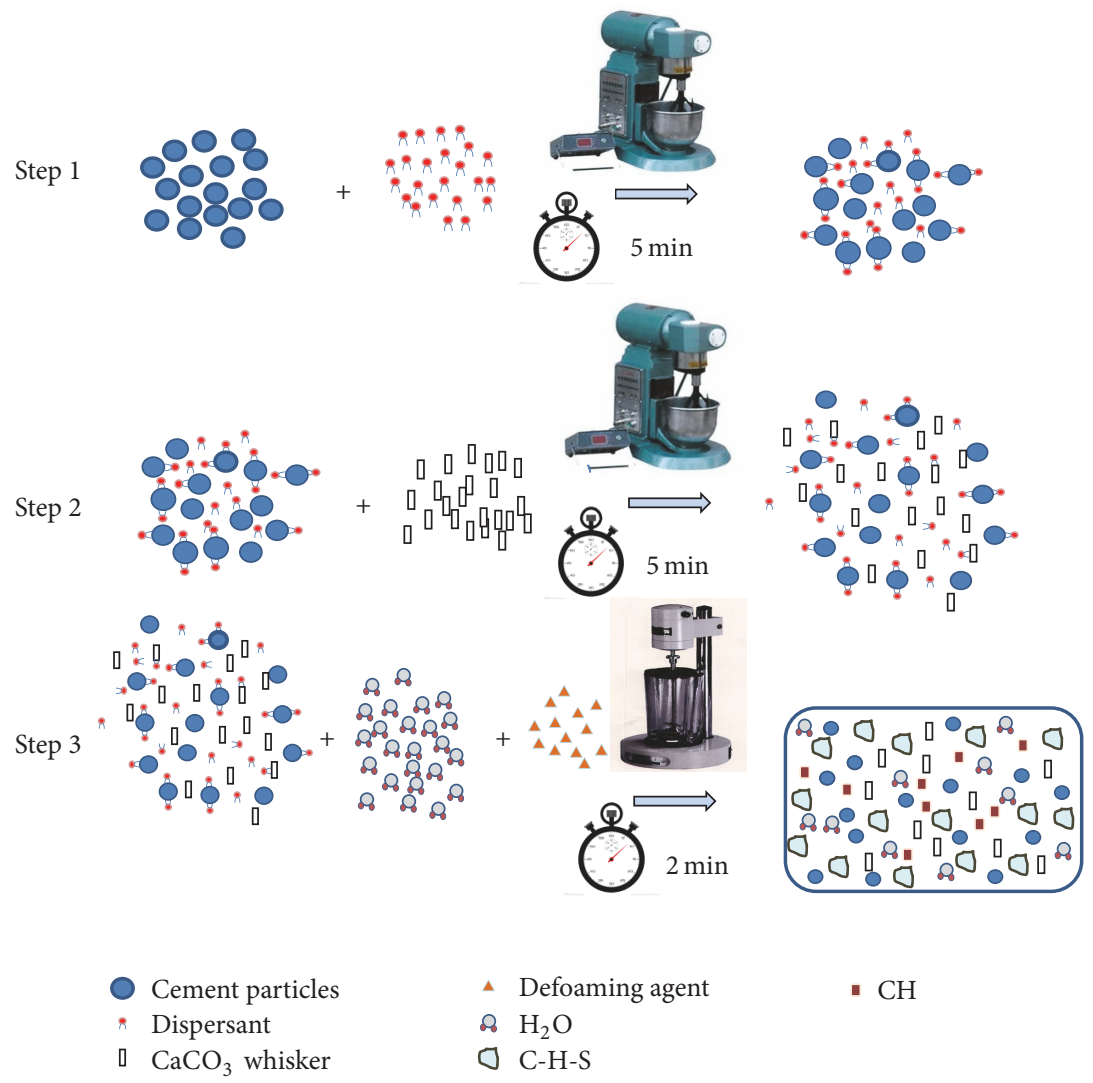

FIGURE 1: The mixing procedure for fresh cement paste mixtures.

Afterwards, the curing condition of the cement slurry was under the relative humidity $95 \%$ and $30^{\circ} \mathrm{C}$ for 7 days as preparation.

The split tensile strength of the cement pastes was test based on the Chinese standard "GB/T50081-2002: The Standard of Concrete Mechanics Performance Test Method" and the test specimen size of the cement pastes was $70.7 \mathrm{~mm} \times$ $70.7 \mathrm{~mm} \times 70.7 \mathrm{~mm}$. The uniaxial compression experiment of cement pastes was tested by a CMT-300 universal testing machine with $300 \mathrm{kN}$ maximum test load and 0.5 accuracy index, which was produced by the Shandong Jinan Lian Engineering Testing Technology, Co., Ltd. The test specimen size of the cement pastes for uniaxial compression experiment was $70.7 \mathrm{~mm} \times 70.7 \mathrm{~mm} \times 70.7 \mathrm{~mm}$ as well. The control mode of this experiment was displacement and the loading rate of the experiment was $0.06 \mathrm{~mm} / \mathrm{s}$; additionally the test data was collected by the computer software and the diagram of experimental facility as in Figure 2.

\section{Results and Discussion}

In this part, the macroscopic mechanical properties of split tensile strength, uniaxial compression strength, stressstrain curve, constitutive model, and fracture energy were studied and elucidated. Meanwhile the micrographs of cement pastes fracture with $\mathrm{CaCO}_{3}$ whiskers and the reinforcing effect were also shown and elaborated as follows.
3.1. The Split Tensile Strength. Under the oil well, the cement sheath would be easily destroyed by the tensile stress. Therefore the split tensile strength of the cement pastes with different dosage of the $\mathrm{CaCO}_{3}$ whisker was presented in Figure 3. With the increasing of the $\mathrm{CaCO}_{3}$ whisker, the improving trend of cement pastes tensile strength has taken place. Thereafter, the dosage exceeded $10 \%$; the tensile strength started to decrease significantly. At the $10 \%$ point, the growth of the tensile strength was increased by $54 \%$ as the highest comparing to the control sample. With high mechanical strength, the $\mathrm{CaCO}_{3}$ whisker could fill in the cement and restrict the formation and propagation process of the microcrack $[12,13]$. At the dosage of $\mathrm{CaCO}_{3}$ whisker of $15 \%$, the tensile strength of the cement pastes has fallen down seriously. Hereby, over this dosage, the $\mathrm{CaCO}_{3}$ whisker could not be dispersed well and the cement material was decreased so that the $\mathrm{CaCO}_{3}$ whisker could not be embraced homogeneously by the cement slurry. As in Figure 4, the white dots were marked by red circles, which were the $\mathrm{CaCO}_{3}$ whiskers aggregating on the test-piece failure surface. Thus the added quantity of the $\mathrm{CaCO}_{3}$ whisker was confined from $1 \%$ to $10 \%$ in the next test part of the uniaxial compression.

3.2. The Stress-Strain Curve. Incorporating with different dosages of $\mathrm{CaCO}_{3}$ whisker, the stress-strain curves of the cement pastes were presented in Figure 5, used to assess the contribution of different dosage of $\mathrm{CaCO}_{3}$ whisker. By increasing the $\mathrm{CaCO}_{3}$ whisker, the peak compressive stress 


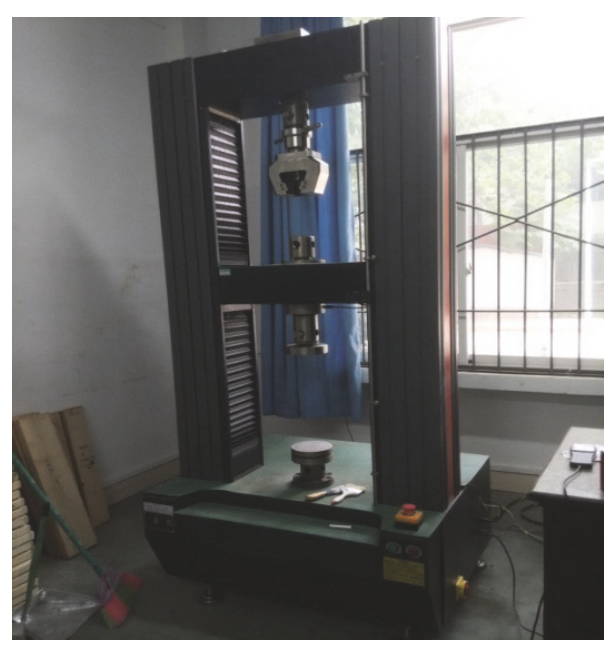

(a)

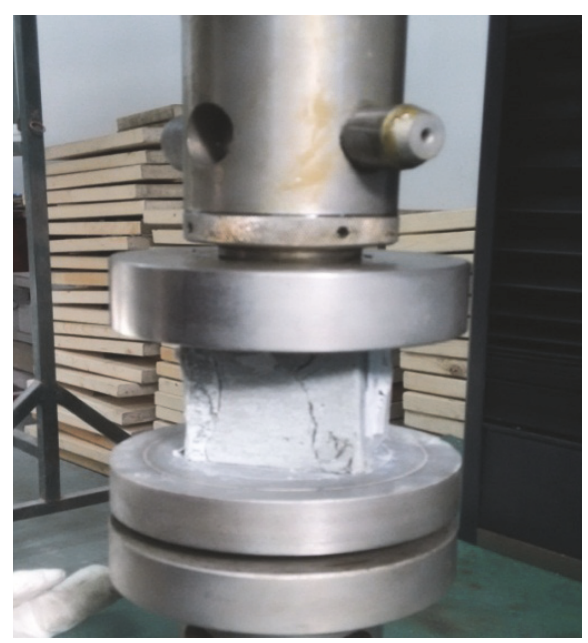

(b)

FIgURE 2: (a) Experimental facility. (b) Uniaxial compression fixture for cement pastes.

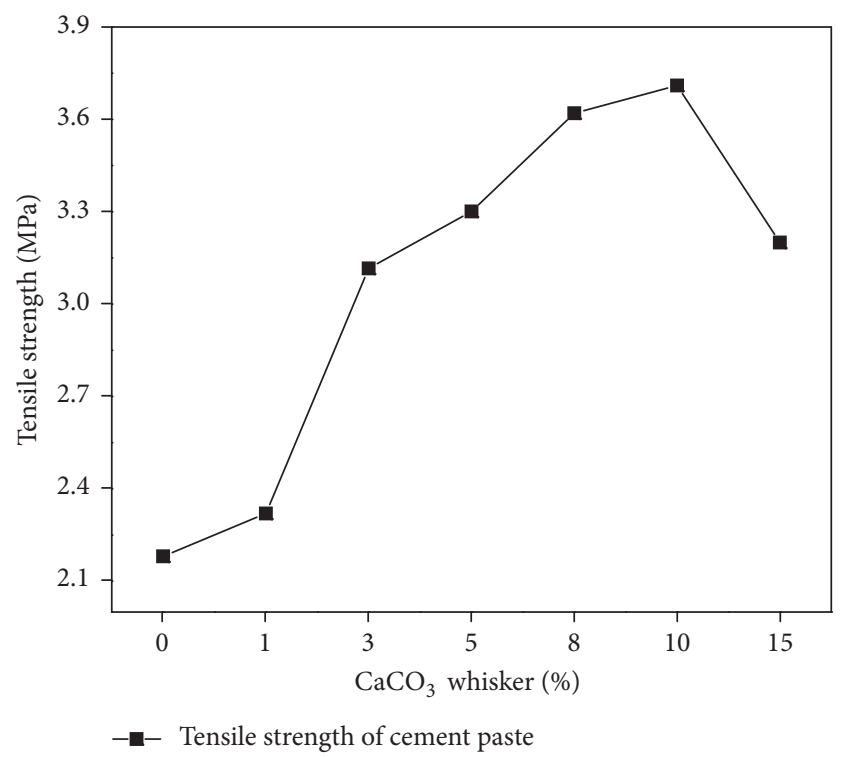

FIgURE 3: Tensile strength of $\mathrm{CaCO}_{3}$ whisker.

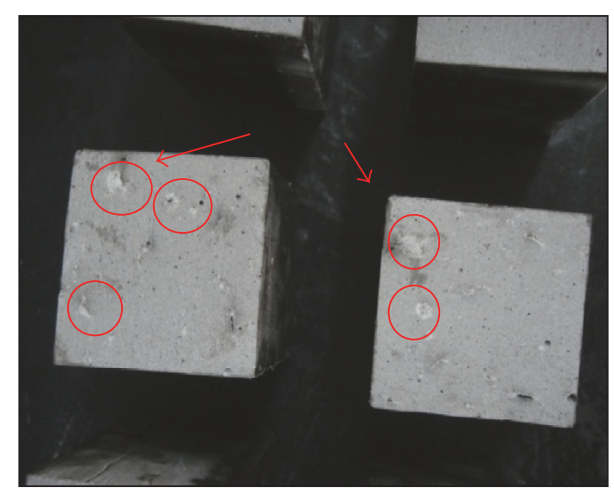

FIGURE 4: The failure surface of test-piece reinforced cement pastes. was improved effectively and each deforming phase was still obvious; hereby that was the possibility of establishing the mathematical model to understand the complete stress-strain process. By increasing the $\mathrm{CaCO}_{3}$ whisker, the stiffness of the cement paste was also improved observably at the elastic stage comparing to the control sample; this improvement was caused by the curve slope and the elasticity modulus rising. Since the peak stress and peak strain were enhanced with the $\mathrm{CaCO}_{3}$ whisker increasing, the deformation energy of the cement pastes could be improved at the elasticplastic deformation stage and the energy analysis would be elucidated in Section 3.4 adequately. Afterward, beyond the ultimate high dosage, the dispersity of $\mathrm{CaCO}_{3}$ whisker in cement slurry had been hindered for further improving. However, as the filling effect, the peak stress of cement paste with high $\mathrm{CaCO}_{3}$ whisker quality could be still higher than the control sample but with reduction of the deformation energy.

The results of uniaxial compression test were shown in Table 3 and the mathematical fitting relationship between $\mathrm{CaCO}_{3}$ whisker and the peak stress was expressed as formula (1). Thereby the fitted curve was shown in Figure 6 and the relationship between $\mathrm{CaCO}_{3}$ whisker and the peak stress was approximately a linear function. This means that the peak stress of the cement paste was increasing with the $\mathrm{CaCO}_{3}$ whisker. The fitting formula between $\mathrm{CaCO}_{3}$ whisker and the elasticity modulus was shown as formula (2), and the fitted curve was shown in Figure 7. The relationship between the $\mathrm{CaCO}_{3}$ whisker and elasticity modulus was likely monomial function; thus the $\mathrm{CaCO}_{3}$ whisker had reinforced the elasticity modulus of the cement paste well. The relationship between the $\mathrm{CaCO}_{3}$ whisker and peak strain was exhibited in Figure 8, which showed that the peak strain was fluctuated from 0.6 to 0.8 with different dosage of $\mathrm{CaCO}_{3}$ whisker. Thereby it could not be ruled and the $\mathrm{CaCO}_{3}$ whisker could hardly impact the peak strain of cement pastes.

$$
\mathrm{Fc}=2.86 \mathrm{Nf}+128.32
$$


TABLE 3: The result of uniaxial compression test.

\begin{tabular}{lccc}
\hline $\begin{array}{l}\text { Dosage of } \\
\mathrm{CaCO}_{3} \\
\text { whisker }\end{array}$ & $\begin{array}{c}\text { Peak stress } \\
(\mathrm{kN})\end{array}$ & $\begin{array}{c}\text { Peak strain } \\
(\mathrm{mm})\end{array}$ & $\begin{array}{c}\text { Elasticity modulus } \\
\left(\mathrm{N} / \mathrm{mm}^{2}\right)\end{array}$ \\
\hline 0 & 128.80 & 1.89 & 1356.97 \\
$3 \%$ & 136.50 & 1.41 & 1564.12 \\
$5 \%$ & 140.40 & 1.69 & 1473.30 \\
$8 \%$ & 155.70 & 1.87 & 1418.84 \\
$10 \%$ & 154.50 & 2.03 & 1387.21 \\
\hline
\end{tabular}

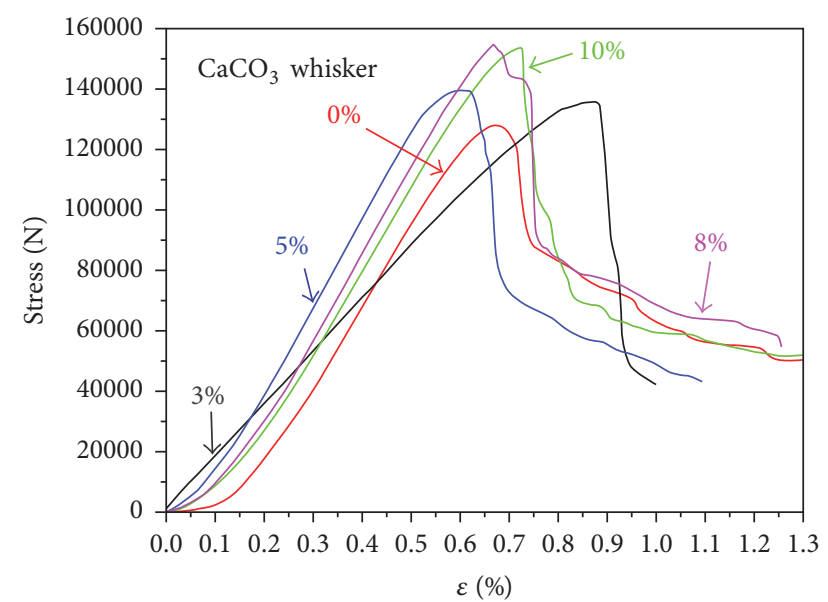

FIGURE 5: The stress-strain curve of different $\mathrm{CaCO}_{3}$ whisker dosage cement pastes.

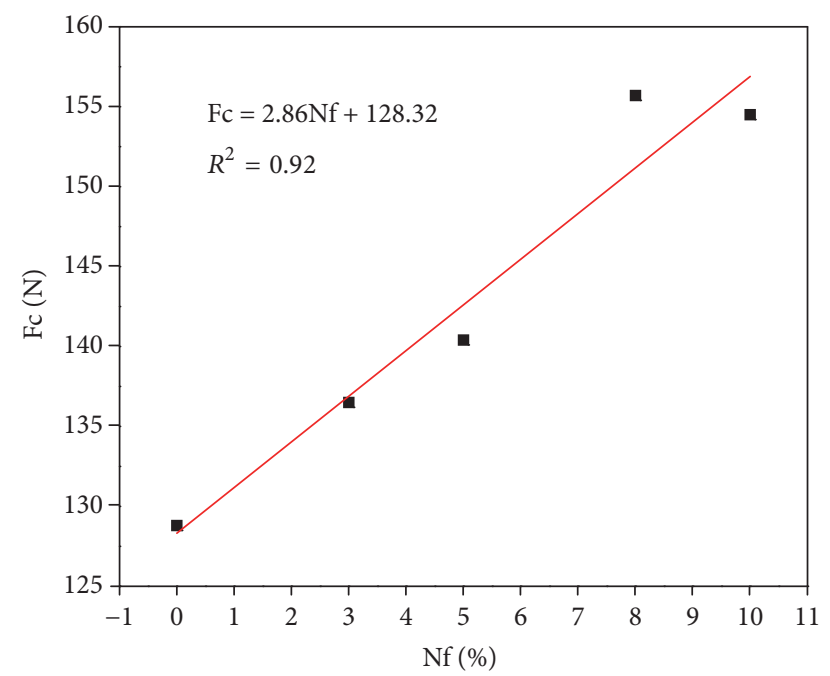

FIGURE 6: Plot of peak stress against $\mathrm{CaCO}_{3}$ whisker.

$$
E=18.19 \mathrm{Nf}^{-0.10}
$$

where the $\mathrm{Fc}, \mathrm{Nf}$, and $E$ were with respect to the peak stress, $\mathrm{CaCO}_{3}$ whisker dosage, and elasticity modulus.

3.3. The Constitutive Model of Stress-Strain Curve. Figure 5 showed that although the stress-strain curves of $\mathrm{CaCO}_{3}$

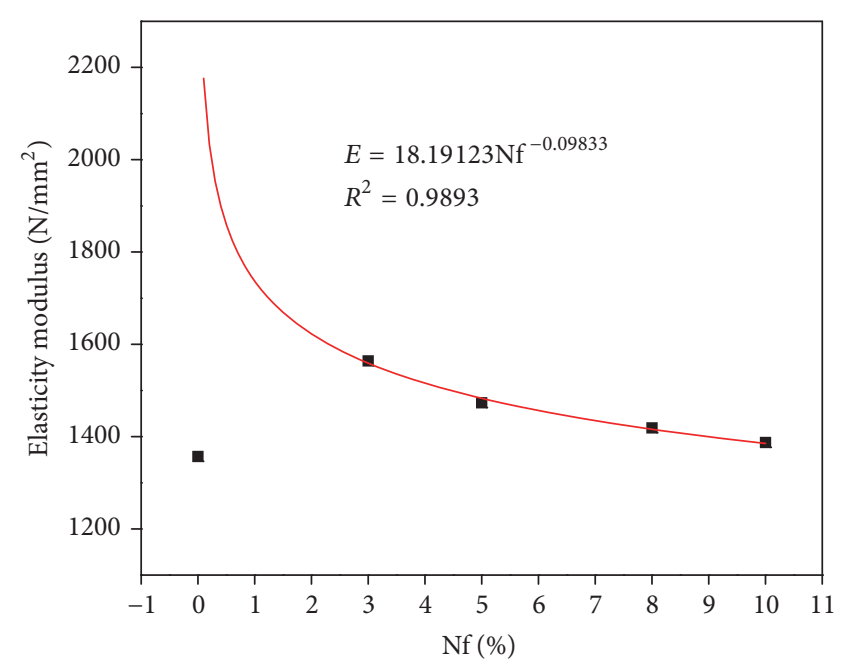

Figure 7: Plot of elasticity modulus against $\mathrm{CaCO}_{3}$ whisker.

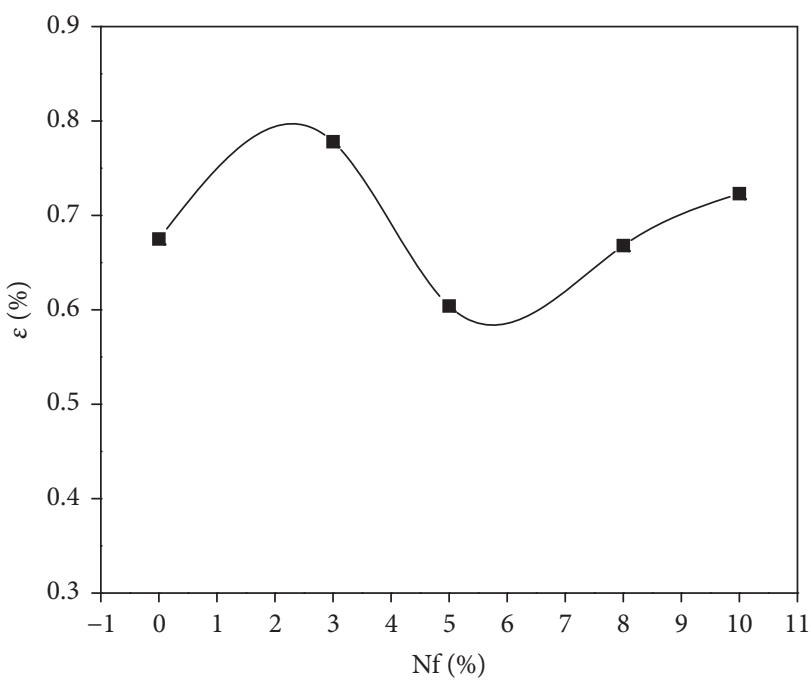

$\mathrm{CaCO}_{3}$ whisker reinforced cement paste

FIgURE 8: Plot of peak strain against $\mathrm{CaCO}_{3}$ whisker.

whisker were at different dosage, the basic geometrical characteristics and processes of the uniaxial compression test were similar. A test result of experiment was chosen to illustrate the typical fiber reinfoced cement uniaxial stress-strain curve 


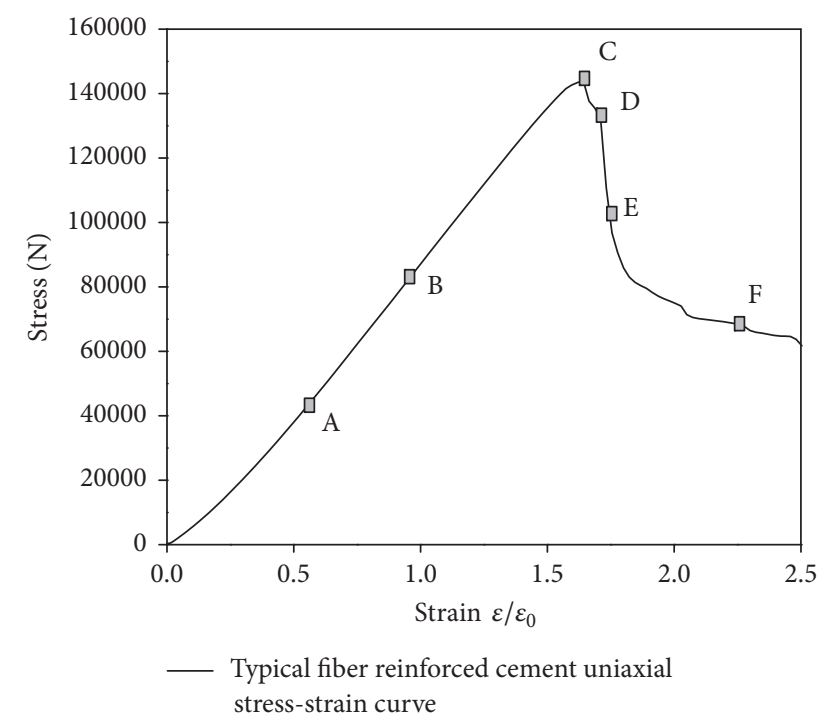

FIgURE 9: Typical fiber reinforced cement uniaxial stress-strain curve.

in Figure 9. Meanwhile the constitutive model of $\mathrm{CaCO}_{3}$ whisker cement pastes stress-strain curve was established and analyzed in this part. A new mathematic relation was proposed in this part, which was enlightened by Zhenhai Guo from Tsinghua University [11].

(1) The stress-strain curve of $\mathrm{CaCO}_{3}$ whisker reinforced cement paste was split into two parts as ascent stage and descent stage for fitting and analyzing as follows:

$$
\begin{aligned}
& y=a_{0}+a_{1} x+a_{2} x^{5}+a_{3} x^{6} \\
& (x \leq 1) \text { the equation of ascent stage } \\
& y=\frac{x}{b_{0}+b_{1} x+b_{2} x^{2}}
\end{aligned}
$$

$(x \geq 1)$ the equation of descent stage,

where $x=\varepsilon / \varepsilon_{p}, y=\delta / \delta_{p}$, and $\varepsilon$ and $\delta$ were the stress and strain. $\varepsilon_{p}, \delta_{p}$ were the peak strain and peak stress and $a_{0}, a_{1}, a_{2}, a_{3}, b_{0}, b_{1}, b_{2}$ were the calculating parameters of the curve.

(2) The ascent stage $(0 \leq x \leq 1)$ is as follows.

As the stress-strain curve showed, $a_{0}, a_{1}, a_{2}$, and $a_{3}$ should fit the geometrical feature as follows:

(A) The curve went through the origin and that meant when $x=0$, then $y=0$.

(B) When $0 \leq x<1, \partial^{2} y / \partial x^{2}<0$, the slope $(d y / d x)$ of ascent stage decreased monotonously and with no inflection point.

(C) $x=1, d y / d x=0, y=1$ was the necessary condition of the peak point $\mathrm{C}$ on the curve.

Taking (A), (B), and (C) conditions into (3), calculate the results as $a_{0}=0, a_{2}=6-5 a_{1}$ and $a_{3}=4 a_{1}-5$. Afterwards, to solve the problem was subject to calculating the independent parameter $a_{1}$.
Then (3) was turned into

$$
y=a_{1} x+\left(6-5 a_{1}\right) x^{5}+\left(4 a_{1}-5\right) x^{6} .
$$

From (3), when $x=0$, then $d y / d x=a_{1}$.

Thus the following could be obtained:

$$
a_{1}=\left.\frac{d y}{d x}\right|_{x=0}=\left.\frac{d\left(\delta / \delta_{p}\right)}{d\left(\varepsilon / \varepsilon_{c}\right)}\right|_{x=0}=\frac{d \delta /\left.d \varepsilon\right|_{x=0}}{\delta_{p} / \varepsilon_{c}}=\frac{E_{0}}{E_{p}},
$$

where the $E_{0}=\left.(d \delta / d \varepsilon)\right|_{x=0}\left(\mathrm{~N} / \mathrm{mm}^{2}\right)$ was the elasticity modulus of initial tangent of the cement pastes and $E_{p}=$ $\delta_{p} / \varepsilon_{c}\left(\mathrm{~N} / \mathrm{mm}^{2}\right)$ was the ratio between the peak strength and peak strain as the secant modulus of the peak point of the curve, while $a_{1}$ was the ratio of the initial tangent modulus and secant modulus. The ascent stage of the curve could be calculated by Ec and Ep. Meanwhile the curve also fit condition (B), when $0 \leq x<1$ and $\partial^{2} y / \partial x^{2}<0$; then the following could be obtained:

$$
\begin{aligned}
& \text { when } x=1 \text { as } \frac{\partial^{2} y}{\partial x^{2}} \\
& =20\left(6-5 a_{1}\right) x^{4}+30\left(4 a_{1}-5\right) x^{5} \leq 0 \\
& \begin{aligned}
(x=1) & \longrightarrow 20\left(6-5 a_{1}\right)+30\left(4 a_{1}-5\right) \leq 0 \\
& \longrightarrow 20 a_{1} \leq 30 \\
& \longrightarrow a_{1} \leq 1.5 \\
\text { also the } a_{1} & =\left(\frac{E_{0}}{E_{p}}\right) \mathrm{Ec}>0,
\end{aligned}
\end{aligned}
$$

$$
\text { Ep }>0 \text {, then } a_{1}>0,0<a_{1} \leq 1.5 .
$$

The plots of the calculated curves at the ascent stage with different $a_{1}$ were shown in Figure 10. When $a_{1}>1.5$, at the top part of the curve that was violated the actual test results were caused by $y>1$. Simultaneously, the calculated results were contrasted with the actual test curves as Figure 11 (where the solid lines showed the calculation and the dashed lines showed the test samples). When $a_{1}<0.6$, the calculating curve could not fit the test result without an inflection point. Therefore, the data range of the $a_{1}$ could be suggested as

$$
0.5<a_{1} \leq 1.5 .
$$

(3) The descent stage $(x \geq 1)$ is as follows.

As the stress-strain curve showed, $b_{0}, b_{1}$, and $b_{2}$ should fit the geometrical feature as follows:

(A) When $x=1, d y / d x=0$, and $y=1$ the curve should reach peak point $C$.

(B) When $\partial^{2} y / \partial x^{2}=0, x_{\mathrm{D}}>1.0$, hereby there was another inflection point as $\mathrm{D}$.

(C) When $\partial^{3} y / \partial x^{3}=0, x_{E}\left(>x_{D}\right)$, then the maximum curvature point of the descent stage was $\mathrm{E}$.

(D) When $x \rightarrow \infty, y \rightarrow 0$ and $d y / d x \rightarrow 0$, the descent stage of the curve would be extended indefinitely and converged to coordinate axis without intersects; thus the whole curve should fit $x \geq 0,0<y \leq 1$. 


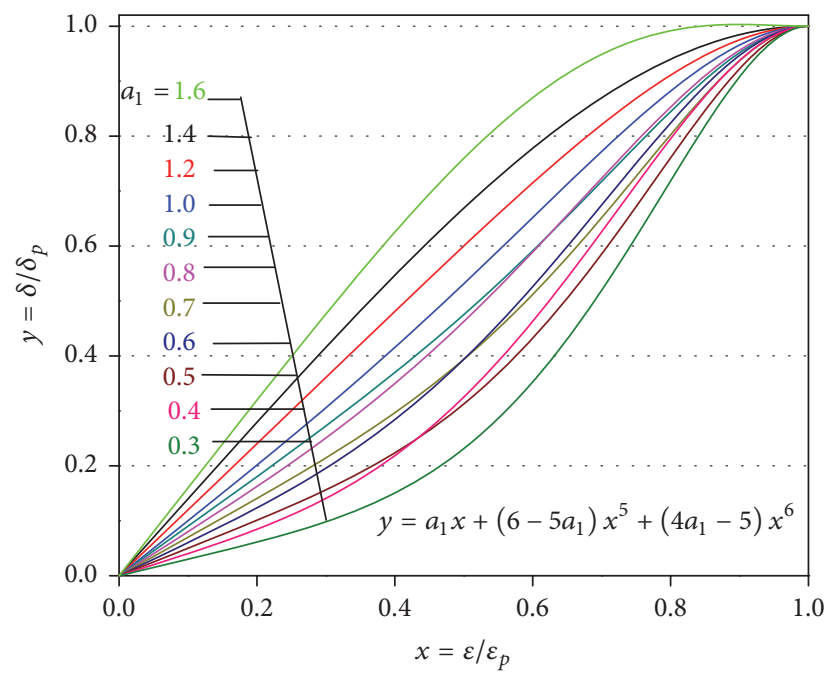

FIgURE 10: $a_{1}$ and the calculated curve at the ascent stage.

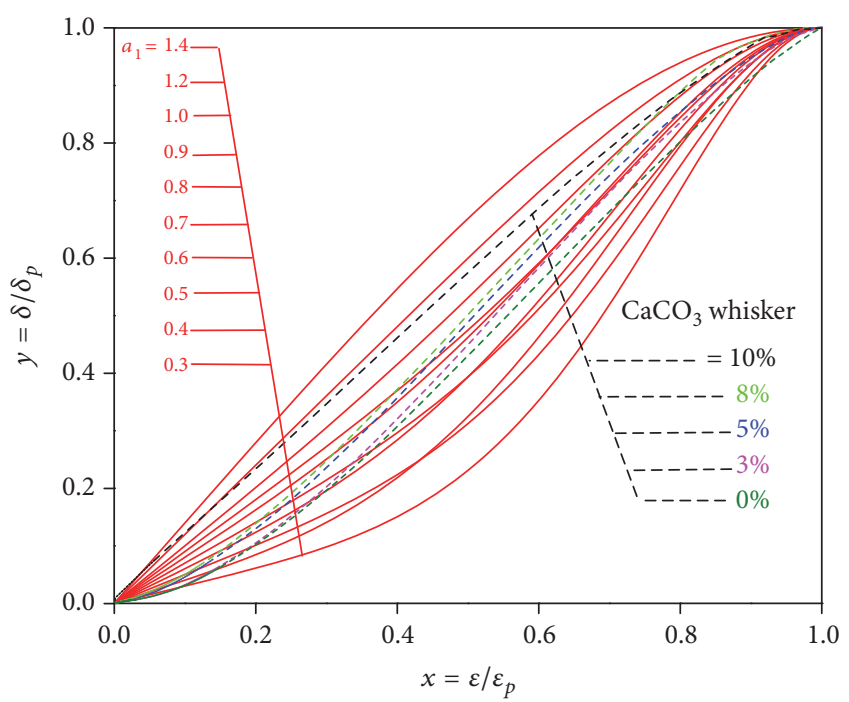

FIGURE 11: The calculated curve contrast to the test curve.

To take (A) into (4) this would obtain the result as $b_{1}=$ $1-2 b_{0}, b_{2}=b_{0}$ that could left the only parameter as $b_{0}$. Then (4) would change as

$$
y=\frac{x}{b_{0}(x-1)^{2}+x} \quad x \geq 1 .
$$

Equation (9) should fit the conditions of (C) and (D). When $b_{0}=0$, then $y \equiv 1$.

As the curve presented when $b_{0} \rightarrow \infty$, then $y \rightarrow 0$ and after peak point $C$, the residual stress of the cement paste was approaching 0 and at this time the cement paste would be considered as fragile material completely.

Based on condition (B), it could be calculated as

$$
\frac{\partial^{2} y}{\partial x^{2}}=\frac{2 b_{0}\left[x^{3}-3 x+\left(2-1 / b_{0}\right)\right]}{\left[b_{0}(x-1)^{2}+x\right]^{3}}=0
$$

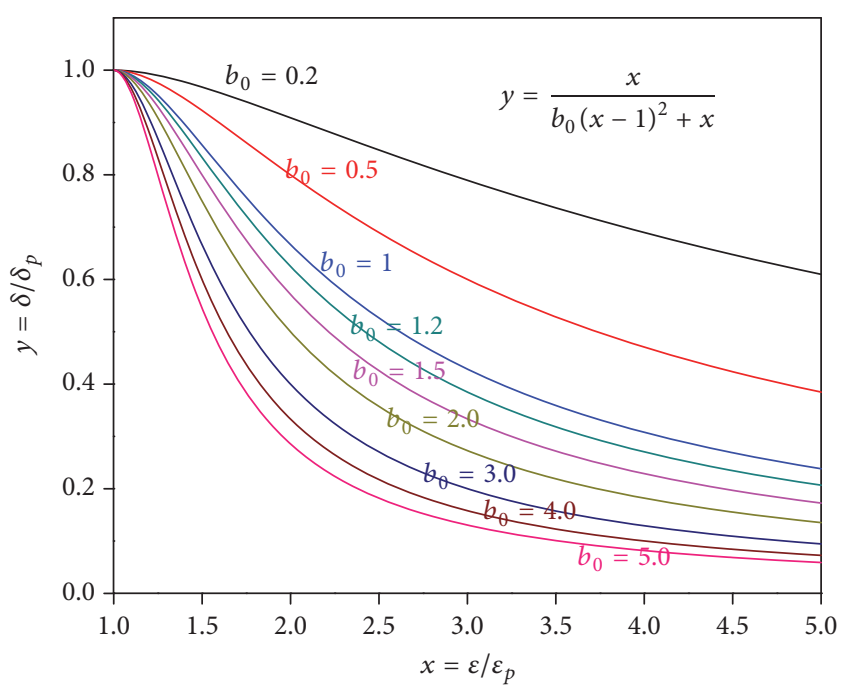

FIGURE 12: $b_{0}$ and the calculated curve at the descent stage.

Afterward, the value of point $\mathrm{D}$ could be calculated (when $x>1$ ) based on condition (C) and that would be

$$
\begin{aligned}
& \frac{\partial^{3} y}{\partial x^{3}} \\
& =\frac{-6 b_{0}\left[b_{0}{ }^{2} x^{4}-6 b_{0}{ }^{2} x^{2}+\left(8 b_{0}{ }^{2}-4 b_{0}\right) x-\left(3 b_{0}{ }^{2}-4 b_{0}+1\right)\right]}{\left[b_{0}(x-1)^{2}+x\right]^{3}} \\
& =0 .
\end{aligned}
$$

Then the maximum curvature point $\mathrm{E}$ could be also calculated $\left(x_{\mathrm{E}}>x_{\mathrm{D}}\right)$.

The descent stage of the curves against different $b_{0}$ was shown in Figure 12. When $b_{0}=0.2$ or $b_{0}=0.5$, the curve of the descent stage almost was linear, and inflection point $\mathrm{D}$ and maximum curvature point E were nonsignificant. Simultaneously, though the test-piece was deformed seriously, the spice was still with high strength which could not fit the actual test result.

The calculated curves were contrasted with the actual test curves in Figure 13. The shape of descent stage of the $\mathrm{CaCO}_{3}$ whisker reinforced cement paste was complicated and the shape was effectively impacted by increasing the $\mathrm{CaCO}_{3}$ whisker dosage. Figure 13 showed the descent stage was with a large range of residual stress, when the residual stress of the cement paste had fallen below $60 \%$ that would determine that the cement paste was complete failure in this script, which was because the cement paste was covered with macroscopic crack and destroyed seriously at this moment. From the above, the range of $b_{0}$ of the descent stage curve was suggested to belong to $5<b_{0}<500$.

The above calculating equations of the stress-strain curve were focused on the $\mathrm{CaCO}_{3}$ whisker reinforced cement paste and were under a definitive water-cement ratio. When the conditions were changed the equations should be amended as well.

(4) The complete curve is as follows. 


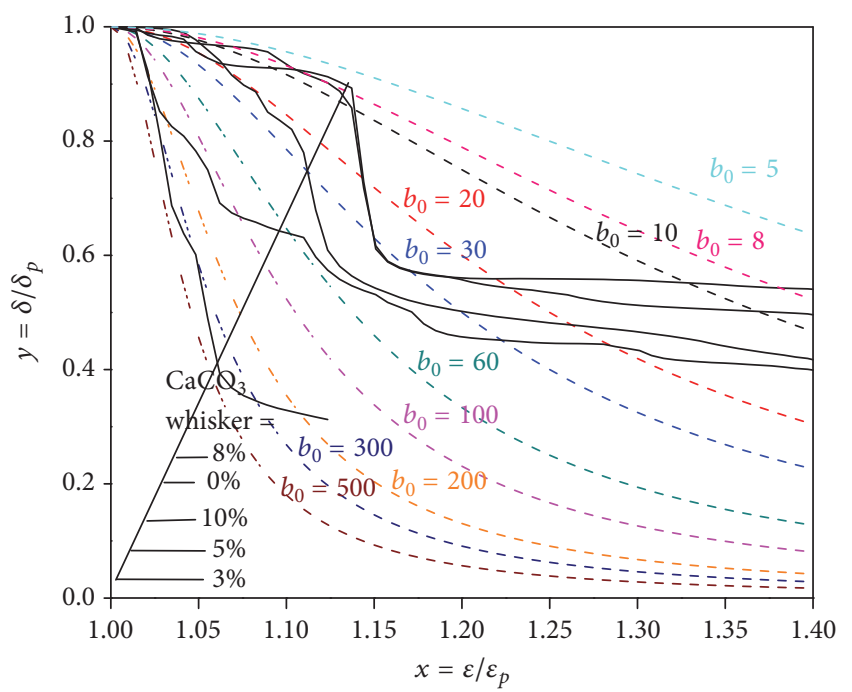

FIGURE 13: Calculating curve in contrast to the test curve.

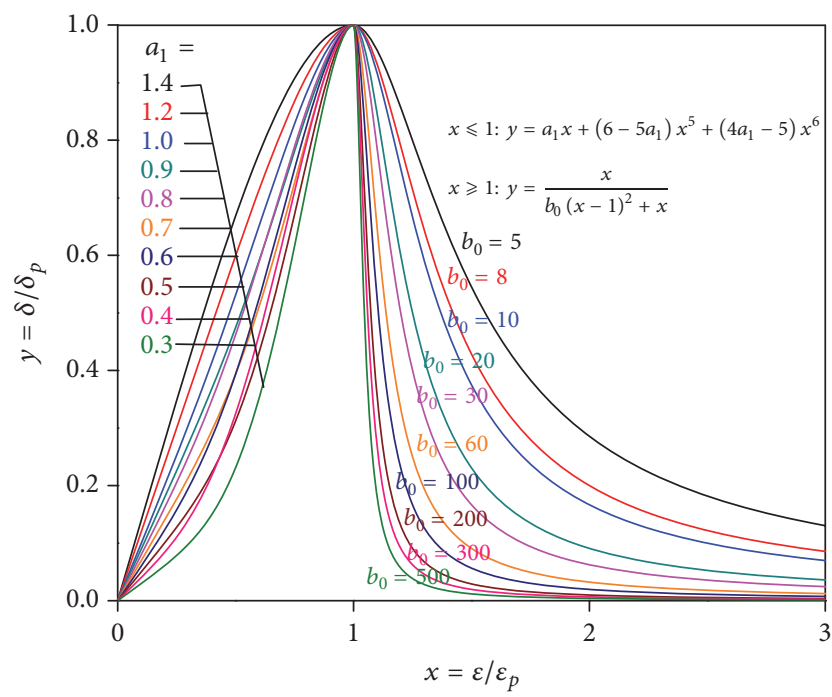

FIgURE 14: The calculating curve of constitutive model.

To sum up, the equations of (5) and (9) were combined together to represent the constitutive model of the stressstrain curves in Figure 14, and the constitutive model was contrasted to the test curves in Figure 15. The results of the experiment curves were all contained by the calculating curves, so the fitted equation would be effective, especially at the ascent stage and the descent stage before the stress below $60 \%$. After the stress had fallen below $60 \%$, the cement paste would be destroyed completely, which was considered to lose the research value.

The constitutive model of stress-strain curve of the $\mathrm{CaCO}_{3}$ whisker reinforced cement paste could be described by (5) and (9) as

$$
\begin{aligned}
& y=a_{1} x+\left(6-5 a_{1}\right) x^{5}+\left(4 a_{1}-5\right) x^{6}, \quad 0 \leq x \leq 1 \\
& y=\frac{x}{b_{0}(x-1)^{2}+x}, \quad x \geq 1,
\end{aligned}
$$

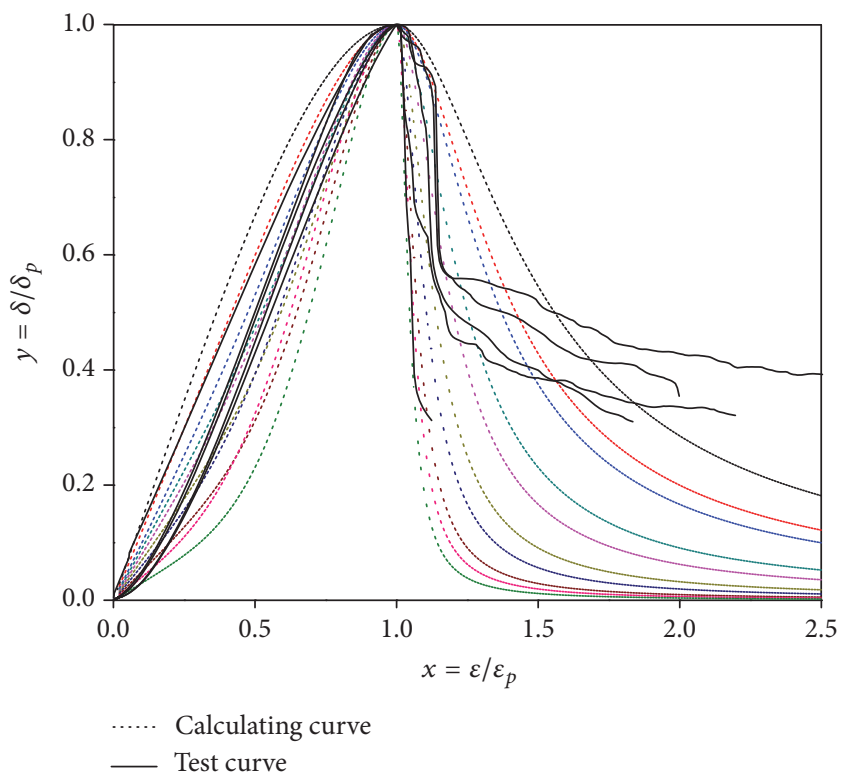

FIgURE 15: The integrated calculating curve in contrast to the complete test curve. The colored dotted lines referred to the incorporation of calculated results in Figures 11 and 13.

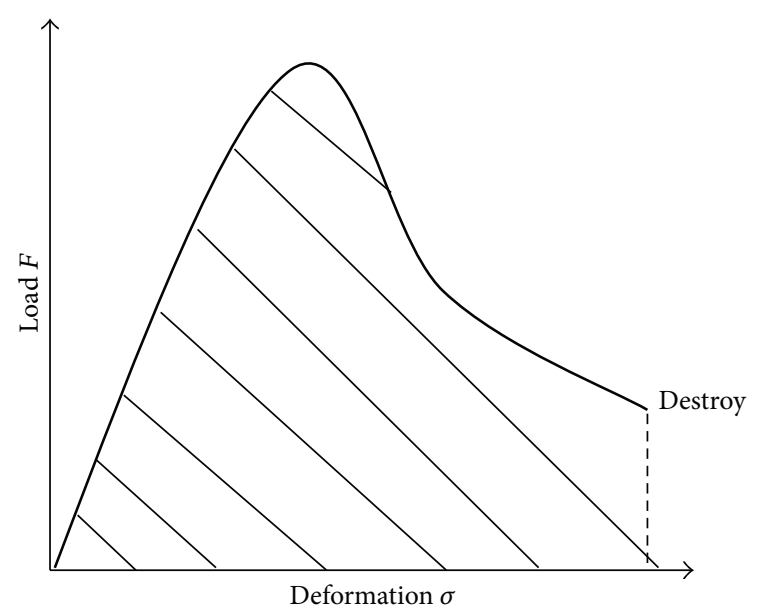

FIgURE 16: The toughness of the material.

where $a_{1}$ and $b_{0}$ were undecided parameters and the range of $a_{1}$ and $b_{0}$ of the $\mathrm{CaCO}_{3}$ whisker reinforced cement paste was elaborated as $0.5<a_{1} \leq 1.5,5<b_{0}<500$ in this script.

3.4. Toughness of Uniaxial Compression. The toughness of the cementitious material was focused on the ability of absorbing energy from initial loading to materials failure; the more the energy was absorbed, the more tough the cementitious material would be. The absorbing energy of the material under uniaxial compression was calculated by the area of the stress-strain curve in Figure 16. The work of the load could be calculated by

$$
W=\int F d \sigma
$$




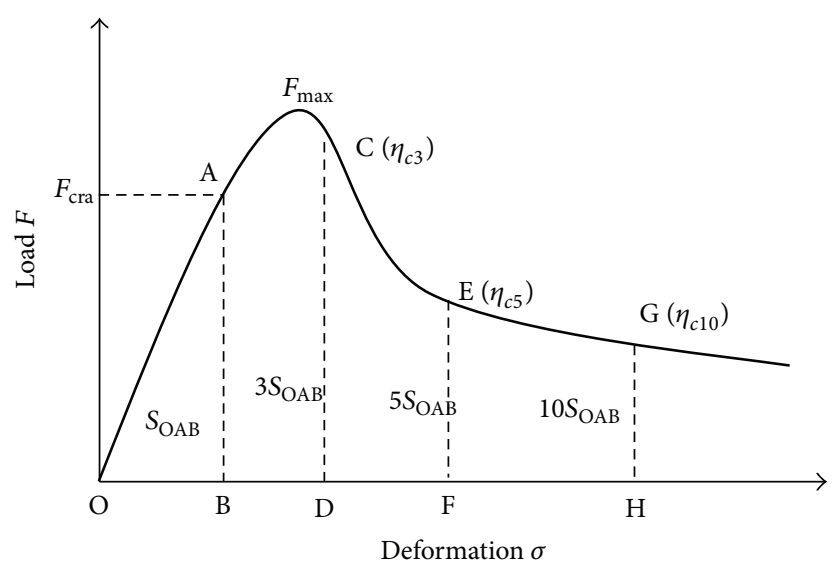

FIGURE 17: The stress-strain curve and toughness index.

where $W, F$, and $\sigma$ were the load work, load, and the strain capacity.

The toughness of the cementitious material was related not only to the bearing capacity but also to the mechanical deformation capability. In this script, the toughness of the cementitious material which was calculated referring to the Chinese standard of "Steel Fiber Reinforced Concrete Testing Methods (CECS13: 2009)" and was elucidated as follows.

(1) The compression curve of the cement was divided into 4 parts in Figure 17, drawing a straight line though the $x$-axis at the point of $F_{\text {cra }}$ (where $F_{\text {cra }}=0.85 * F_{\max } ; F_{\max }$ was the peak stress), which was parallel to the $y$-axis and intersected the load curve at the critical point A. The $x$-axis of point A was the critical elastic deformation as $\sigma_{\text {cra }}$ and the area of $S_{\mathrm{OAB}}$ was defined as critical toughness of $S_{\mathrm{OAB}}$.

(2) Calculate the values of $1.2,1.5$, and 2.0 times of $\sigma_{\text {cra }}$, respectively, which were determined as the points $\mathrm{D}, \mathrm{F}$, and $\mathrm{H}$ on the load curve. The areas of $S_{\mathrm{OAB}}, S_{\mathrm{OACD}}, S_{\mathrm{OAEF}}$, and $S_{\mathrm{OAGH}}$ were also calculated. Hereby, the toughness indexes were defined as follows:

$$
\begin{aligned}
& \eta_{c 1.0}=\frac{S_{\mathrm{OF}}{ }_{\text {max }}}{S_{\mathrm{OAB}}} \\
& \eta_{c 1.2}=\frac{S_{\mathrm{OACD}}}{S_{\mathrm{OAB}}} \\
& \eta_{c 1.5}=\frac{S_{\mathrm{OAEF}}}{S_{\mathrm{OAB}}} \\
& \eta_{c 2.0}=\frac{S_{\mathrm{OAGH}}}{S_{\mathrm{OAB}}} .
\end{aligned}
$$
lows:

(3) The capability coefficients index was defined as fol-

$$
\zeta=\frac{\eta_{c, n}-a}{a-1}
$$

where $a$ was the deformation value as $1.2,1.5$, and 2.0 and $\eta_{c, n}$ was the toughness index relating to the deformation value in Table 4 .

The relationships between the toughness index or capability coefficients index and the dosage of the $\mathrm{CaCO}_{3}$ whisker

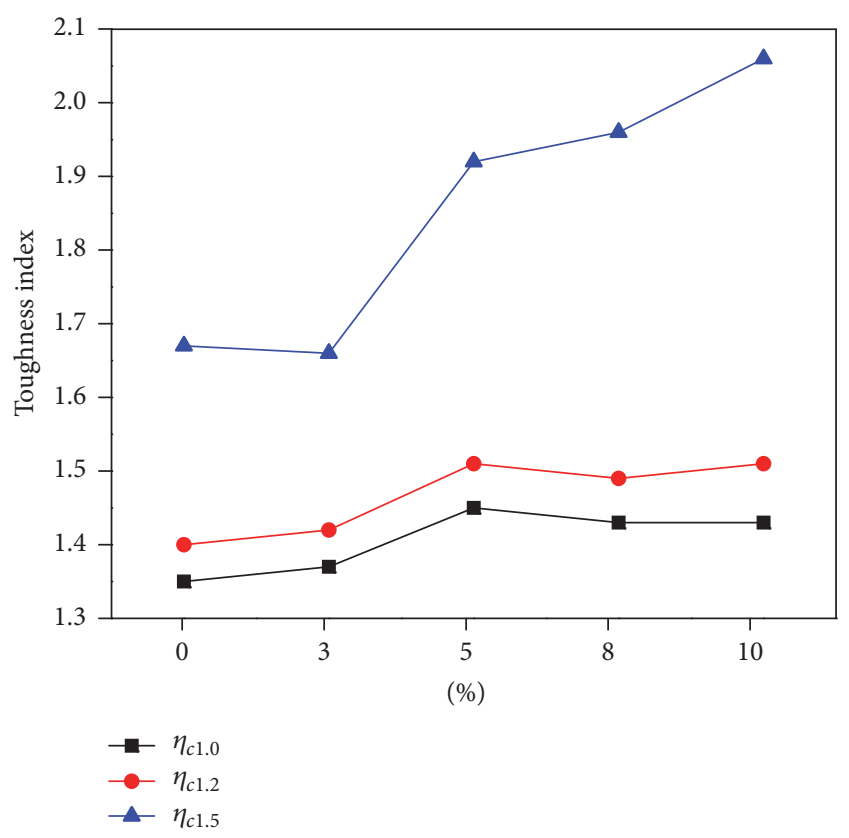

FIgURE 18: The toughness index of $\mathrm{CaCO}_{3}$ whisker reinforced cement paste.

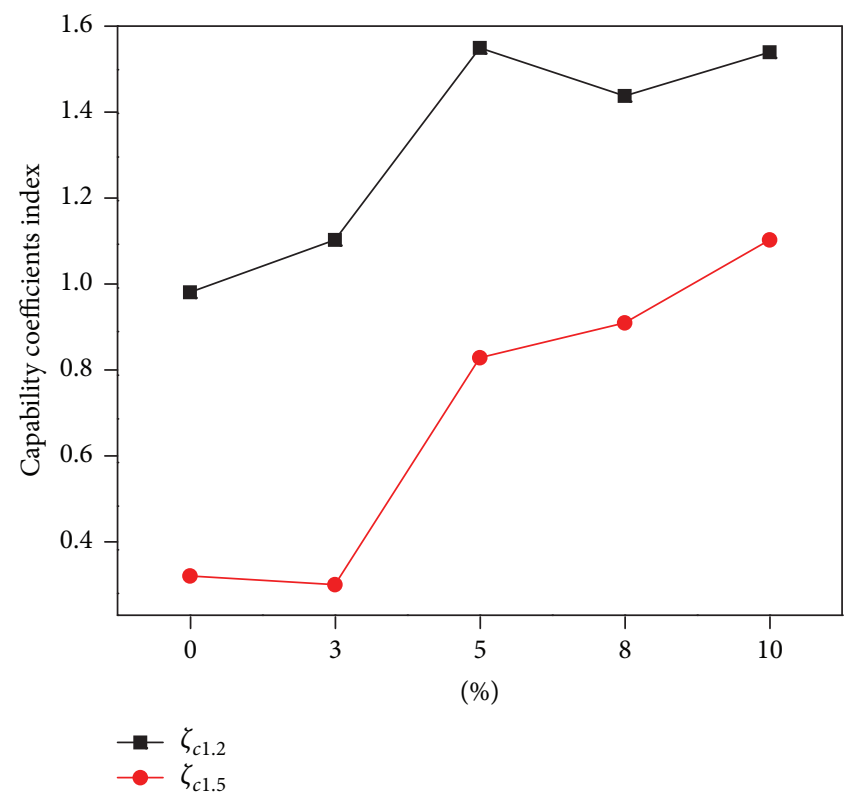

FIGURE 19: Capability coefficients index of $\mathrm{CaCO}_{3}$ whisker reinforced cement paste.

were shown in Figures 18 and 19. The increasing trend of $\eta_{c 1.0}, \eta_{c 1.2}$, and $\eta_{c 1.5}$ was shown in Figure 18 . Additionally, the peak damage energy and the compressive toughness of the cement pastes were developed observably. The growth of $\eta_{c 1.5}$ was most remarkable; at the point $10 \%$ it was improved 1.23 times the control sample. The increasing trend of capability coefficients index of the cement paste was also shown in Figure 19. $\zeta_{c 1.2}$ and $\zeta_{c 1.5}$ of point $5 \%$ were improved 1.57 and 2.47 times the control sample. $\zeta_{c 1.2}$ and $\zeta_{c 1.5}$ of point $10 \%$ were 
TABLE 4: The toughness index and capability coefficients index.

\begin{tabular}{|c|c|c|c|c|c|}
\hline \multirow{2}{*}{$\begin{array}{l}\mathrm{CaCO}_{3} \text { whisker } \\
\text { quality }\end{array}$} & \multicolumn{5}{|c|}{$\eta_{c, n}$} \\
\hline & $\eta_{c 1.0}$ & $\eta_{c 1.2}$ & $\eta_{c 1.5}$ & $\zeta_{c 1.2}$ & $\zeta_{c 1.5}$ \\
\hline $0 \%$ & 1.35 & 1.40 & 1.67 & 0.99 & 0.34 \\
\hline $3 \%$ & 1.37 & 1.42 & 1.66 & 1.11 & 0.32 \\
\hline $5 \%$ & 1.45 & 1.51 & 1.92 & 1.55 & 0.84 \\
\hline $8 \%$ & 1.43 & 1.49 & 1.96 & 1.44 & 0.92 \\
\hline $10 \%$ & 1.43 & 1.51 & 2.06 & 1.54 & 1.11 \\
\hline
\end{tabular}

improved 1.56 and 3.26 times the control sample. Thus the improvement of toughness of the cement paste was further characterized by the energy index as in Table 4 .

\subsection{Micromechanical Mechanisms}

(1) The Microstructure. The $\mathrm{CaCO}_{3}$ whiskers with sharp regularity were inset in the cement pastes which could be identified easily. From Figure 20(a), the cement paste was a kind of inhomogeneity material with small opening where the $\mathrm{CaCO}_{3}$ whiskers with small size could fill in the microcracks and holes. Because of the $\mathrm{CaCO}_{3}$ whiskers with rather higher mechanical strength, when the cement paste was under the stress damage, the $\mathrm{CaCO}_{3}$ whiskers could support the stress as a bridge between the cracks in Figure 20(b), which could expend the destroying energy of the cement matrix by bridging toughening effect [14-16]. In Figure 20(c), caused by the rising stress, the collapsing strength of $\mathrm{CaCO}_{3}$ whiskers far exceeded the cement paste cohesion strength; the crack could not break down the $\mathrm{CaCO}_{3}$ whiskers; instead the $\mathrm{CaCO}_{3}$ whiskers could be pulled out to consume the energy for rubbing action and stripping effect $[15,16]$. Also the crack would be impeded by $\mathrm{CaCO}_{3}$ whiskers $[3,17-$ 20 ] as in Figure 20(d). This was marked by the red circle in Figure 20(e); over the ultimate high dosage, the $\mathrm{CaCO}_{3}$ whiskers could be scattered unevenly; in reverse the whisker would ease the mechanical property of cement paste, whereby the strengthening effort of the $\mathrm{CaCO}_{3}$ whiskers would be summed up as the destroying energy conservation and microcrack inhibiting and a physical model was stated in Figure 20.

(2) Physical Model of Interface Layer. With high draw ratio, the $\mathrm{CaCO}_{3}$ whiskers were short fibers with different granulate material which could bear the longitudinal load. And that was confirmed in mechanical experiment above in this script. A physical interface layer model [21-23] was established to elaborate this mechanism in Figure 21. With a large specific surface area; when the $\mathrm{CaCO}_{3}$ whiskers were blended with the cement slurry, a water molecule layer could be adhered to the surface of $\mathrm{CaCO}_{3}$ whisker, which could promote the cement hydration. Furthermore the $\mathrm{CH}$ crystals would gather in this layer and form a specific fiber-matrix layer between the fiber and cement matrix; this layer consisted of double film layer, $\mathrm{CH}$ gathering layer, and porous layer. The thickness of the double film layer was about 1 2 $\mu \mathrm{m}$, which was composed of $\mathrm{CH}$ crystals and C-S-H. Due to the small size of the $\mathrm{CaCO}_{3}$ whiskers, the double film layer could be bonded with much more fastness to the cement surface compared with the organic fiber which could raise the pull-out energy and inhibit the crack initiation and coalescence [21, 22]. With orienting $\mathrm{CH}$ gathering, the $\mathrm{CH}$ gathering layer was a weak link of the fiber-matrix layer for the loose structure. Another weak link of the fiber-matrix layer was the porous layer with abundant micropores and loose structure which consisted of $\mathrm{CH}$ crystals and $\mathrm{C}-\mathrm{S}-\mathrm{H}$. The thickness of the fiber-matrix layer was about $10 \sim 100 \mu \mathrm{m}$ and $\mathrm{CH}$ gathering layer and porous layer could firmly impact the mechanical strength of the cement paste as the loose structure and constitution. As the fiber spacing theory, the anticracking of the fiber was consanguineously related to the average distance between the reinforcing fiber and the cement matrix; thereby the distance was smaller and the anticracking was stronger. Since the distance was smaller, the thickness of the weak link of the fiber-matrix layer was thinner which indicated that the fiber could adhere the matrix with much fastness; this meant that the mechanical strength was well developed.

As assumed, the $\mathrm{CaCO}_{3}$ whiskers were well dispersed in the three-dimensional direction in the cement paste and the equation of the average distance of the $\mathrm{CaCO}_{3}$ whiskers was shown as follows [24-26]:

$$
\bar{S}=4.88 \frac{\sqrt{V_{f}}}{\text { FSS }},
$$

where $\bar{S}, V_{f}$, and FSS were the average distance $(\mu \mathrm{m})$, fiber volume fraction (\%), and the surface area of the fiber in the unit volume cement matrix $\left(\mathrm{mm}^{2}\right)$.

From (16), when the value of the FSS was increased, $\bar{S}$ would be seriously reduced and the shape of the $\mathrm{CaCO}_{3}$ whiskers was assumed as a uniform cylinder to calculate the FSS:

$$
\mathrm{FSS}_{\mathrm{CaCO}_{3} \text { whisker }}=N P_{f} l_{f}=\frac{\pi d_{f}}{(\pi / 4) d_{f}^{2}} V_{f}=\frac{4}{d_{f}} V_{f},
$$

where

$$
\begin{gathered}
N=\frac{V_{f}}{A_{f} l_{f}}, \\
P_{f}=\pi d_{f},
\end{gathered}
$$

where $N$ was the number of fibers in unit volume cement matrix, $P_{f}$ was the cross-sectional area of the $\mathrm{CaCO}_{3}$ whiskers 


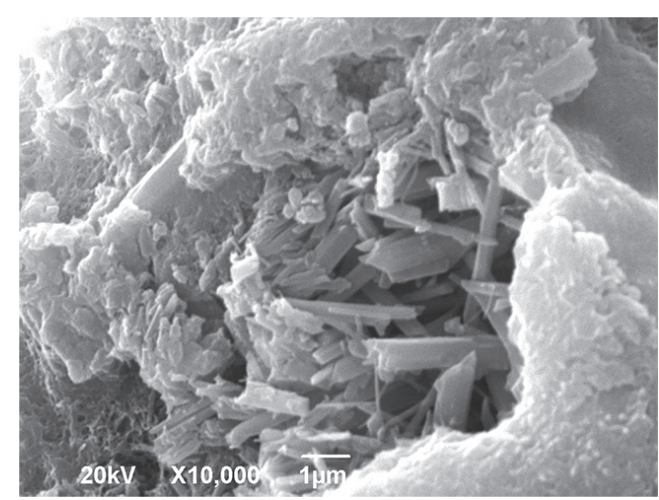

(a)

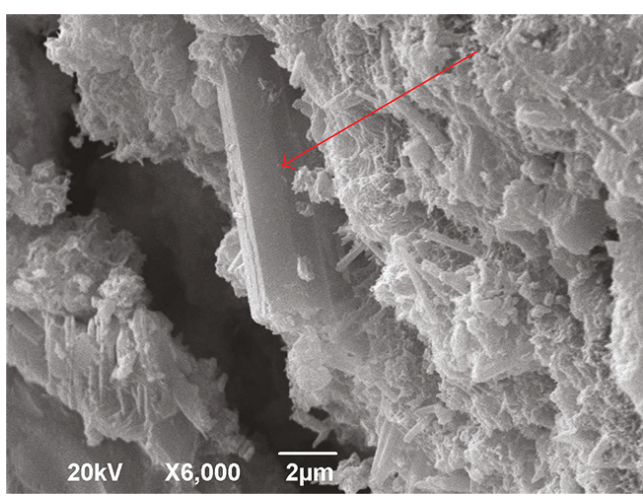

(c)

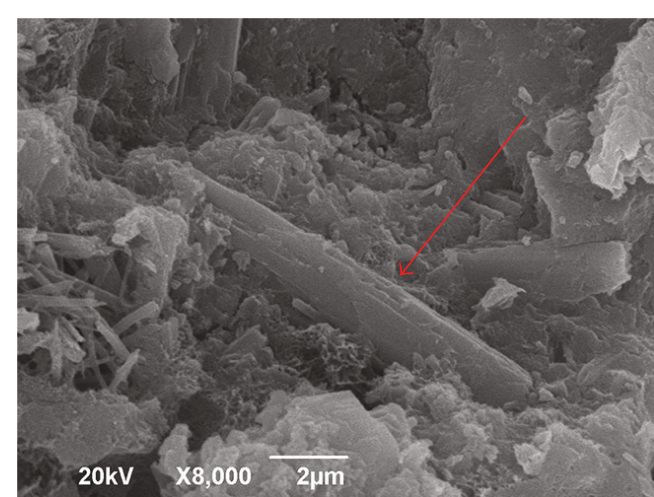

(b)

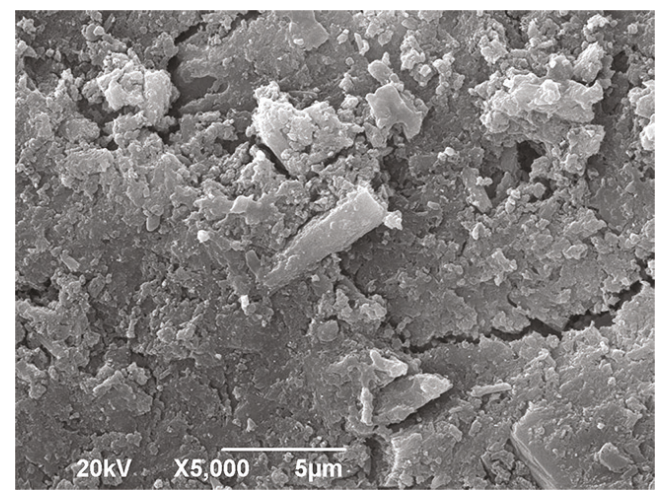

(d)

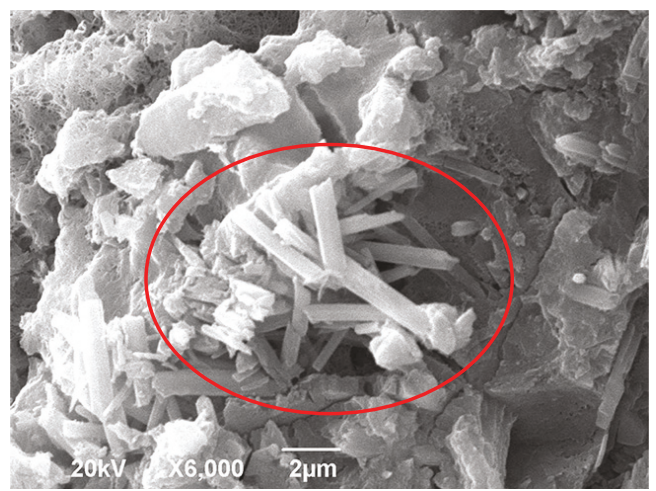

(e)

Figure 20: (a) The $\mathrm{CaCO}_{3}$ whisker filling the crack. (b) The bridging effect of $\mathrm{CaCO}_{3}$ whisker. (c) Pull-out effect of $\mathrm{CaCO}$ whisker. (d) Confined crack developing. (e) the $\mathrm{CaCO}_{3}$ whiskers scattered unevenly.

TABLE 5: The parameters of the physical model.

\begin{tabular}{lcccc}
\hline $\mathrm{CaCO}_{3}$ whiskers $(\%)$ & 1 & 5 & 10 & 15 \\
\hline$V_{f}(\%)$ & 0.67 & 3.40 & 6.60 & 14.80 \\
$\mathrm{FSS}\left(\mu \mathrm{m}^{2} \cdot \mu \mathrm{m}^{-3}\right)$ & 0.027 & 0.136 & 0.264 & 0.592 \\
$\bar{S}(\mu \mathrm{m})$ & 14.84 & 6.16 & 4.75 & 3.17 \\
\hline
\end{tabular}

$\left(\mathrm{mm}^{2}\right)$, and $d_{f}$ was the diameter of the reinforcing fiber $(\mathrm{mm})$.

Under ideal dispersing, the parameters of different dosage of $\mathrm{CaCO}_{3}$ whisker were calculated (where $L=50 \mu \mathrm{m}$ and $d_{f}$ $=1 \mu \mathrm{m}$ ) in Table $5 . \bar{S}$ was over $14 \mu \mathrm{m}$ at $1 \% \mathrm{CaCO}_{3}$ whiskers and the weak link of the fiber-matrix layer was at a relative large scale and the reinforcement of the $\mathrm{CaCO}_{3}$ whiskers was not significant. With the $\mathrm{CaCO}_{3}$ whisker increasing, $\bar{S}$ was decreasing remarkably. And at $10 \% \mathrm{CaCO}_{3}$ whisker, $\bar{S}$ was decreased to $4.75 \mu \mathrm{m}$; hereby the fiber-matrix layer was 


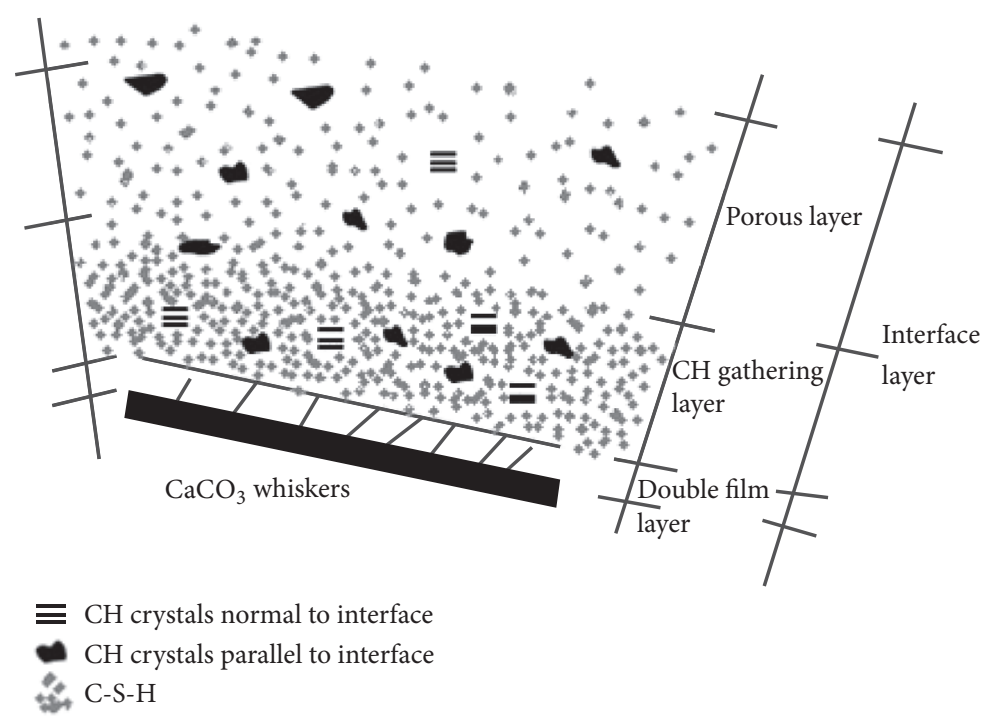

FIgURE 21: Physical model of interface layer.

compressed conspicuously and the tensile strength of the cement paste was well improved under the ideal condition. $\bar{S}$ of the $15 \%$ was the lowest but the strength had still fallen down, because the $\mathrm{CaCO}_{3}$ whiskers could not evenly be dispersed at this dosage; the $\mathrm{CaCO}_{3}$ whiskers could be reunited and would decrease the cementation between the $\mathrm{CaCO}_{3}$ whisker and cement matrix. Thus the fiber spacing theory would be invalid under this mixing condition.

(3) XRD. The results of XRD under $0 \%, 5 \%$, and $10 \%$ of $\mathrm{CaCO}_{3}$ whisker were shown in Figure 22. The types of the hydration products with $\mathrm{CaCO}_{3}$ whiskers were not changed, whereas with the increasing trend of $\mathrm{CaCO}_{3}$ whisker, the diffraction peaks of $\mathrm{C}_{3} \mathrm{~S}$ and the $\mathrm{C}_{2} \mathrm{~S}$ had fallen down; besides the diffracted intensity of the $\mathrm{C}-\mathrm{H}-\mathrm{S}$ and $\mathrm{CH}$ was increased significantly compared with the control sample. Because of the small size and large specific surface area, the $\mathrm{CaCO}_{3}$ whisker was considered as a submicron material; the water molecule layer could be easily adhered to the whisker surface and formed a water firm. The water on the surface of the $\mathrm{CaCO}_{3}$ whisker could stimulate the cement hydration and the hydration products would fix the defect and strengthen the structure of the interface layer. Therefore, the physical model of interface layer had been demonstrated when the C-H-S and $\mathrm{CH}$ were increased significantly after adding $\mathrm{CaCO}_{3}$ whisker.

\section{Conclusion}

(1) With high elasticity modulus and strength, the $\mathrm{CaCO}_{3}$ whisker could improve the tensile strength of the cement paste significantly at the dosage of $10 \%$.

(2) The peak stress, elasticity modulus, and the energy of different stage of the stress-strain curve of the $\mathrm{CaCO}_{3}$ whisker reinforced cement paste were enforced with the increasing of $\mathrm{CaCO}_{3}$ whisker, and the failure characteristics of each stage were observable. The mathematic relations between the peak stress, elasticity, peak strain, and the $\mathrm{CaCO}_{3}$

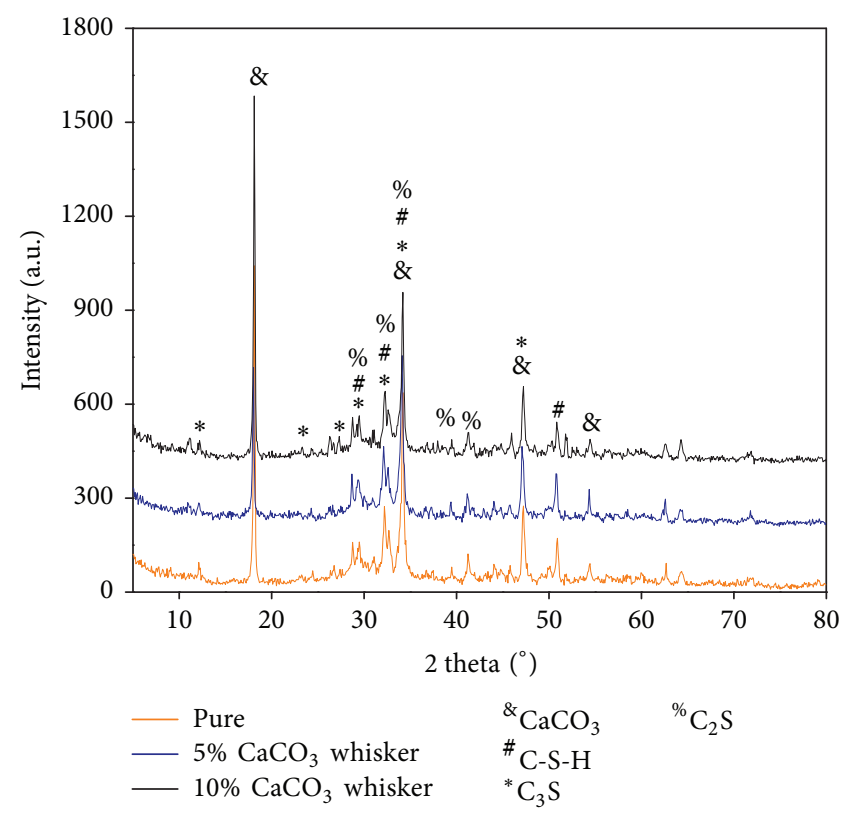

FIGURE 22: The XRD results of $\mathrm{CaCO}_{3}$ whisker reinforce cement pastes.

whisker were discussed. The relation between the peak stress and the $\mathrm{CaCO}_{3}$ whisker was linear relation. Besides, the relation between elasticity and the $\mathrm{CaCO}_{3}$ whisker was power function and the relation between peak strain and $\mathrm{CaCO}_{3}$ whisker was not so regular that the $\mathrm{CaCO}_{3}$ whisker could impact the peak strain of the cement paste barely.

(3) The constitutive model of stress-strain curve of the $\mathrm{CaCO}_{3}$ whisker reinforced cement paste was established in this paper which could describe the stress-strain properties and fit the experimental curve well.

(4) The toughness index and capability coefficients index of the $\mathrm{CaCO}_{3}$ whisker reinforced cement paste were 
established in this paper to elucidate that the $\mathrm{CaCO}_{3}$ whisker could improve the toughness of the cement paste at different stages.

(5) The $\mathrm{CaCO}_{3}$ whisker could develop the strength of cement pastes well and impede the microcracks initiation and coalescence in the cement paste. Caused by the pull-out and bridging effect, the $\mathrm{CaCO}_{3}$ whisker could consume the damaging energy and toughen the cement paste. A physical model of interface layer was also established to elaborate the toughing effect. $\mathrm{CaCO}_{3}$ whisker could form a water firm and the specific interface layer could compress the weak-link layer, improve the mechanical strength of the cement pastes, achieve desirable toughing effects, and improve wellbore integrity.

\section{Conflicts of Interest}

The authors declare that they have no conflicts of interest.

\section{References}

[1] M. Cao, "Research progress of $\mathrm{CaCO}_{3}$ whisker and application in composite materials," in New Chemical Materials, 2010.

[2] M. Cao, J. Wei, and L. Wang, "Serviceability and reinforcement of low content whisker in portland cement," Journal of Wuhan University of Technology-Mater, vol. 26, no. 4, pp. 749-753, 2011.

[3] M. L. Cao, H. Yao, and L. J. Wang, "Experimental study on $\mathrm{CaCO}_{3}$ whisker-reinforced fiber cement mortar," Key Engineering Materials, vol. 477, pp. 245-251, 2011.

[4] M. Cao, C. Zhang, and J. Wei, "Microscopic reinforcement for cement based composite materials," Construction and Building Materials, vol. 40, pp. 14-25, 2013.

[5] M. Li, M. Liu, Y. Yang, Z. Li, and X. Guo, "Mechanical properties of oil well cement stone reinforced with hybrid fiber of calcium carbonate whisker and carbon fiber," Petroleum Exploration and Development, vol. 42, no. 1, pp. 104-111, 2015.

[6] Y. Yuanyi, A well cementing toughening slurry system for gas storage, master thesis, Southwest Petroleum University, 2014.

[7] L. I. Ming, M. Liu, Y. J. Yang, Y. Y. Yang, and X. Y. Guo, Calcium Carbonate Whisker Improved the Performance of Oil and Gas Well Cement, Bulletin of the Chinese Ceramic Society, 2014.

[8] A. Caggiano, G. Etse, P. Folino, M. Ripani, and S. Vrech, Constitutive Formulations for Concrete with Recycled Aggregates, Springer International Publishing, 2017.

[9] H. Chen, S. Wu, and F. Dang, The experimental research on the dynamic and static mechanical characteristics of dam concrete and the constitutive materials, 2016.

[10] H. Qi, Y. Li, X. Chen, J. Duan, and J. Sun, Study of uniaxial constitutive model of concrete in code and development in ABAQUS, 2015.

[11] G. Zhenhai, The Strength of The Concrete and Constitutive Relation, China Architecture and Building Press, 2004.

[12] S. Grünewald and J. C. Walraven, "Parameter-study on the influence of steel fibers and coarse aggregate content on the fresh properties of self-compacting concrete," Cement and Concrete Research, vol. 31, no. 12, pp. 1793-1798, 2001.

[13] Z. Wang and P. U. Xin, "Experimental study on the uniaxial compression properties and the stress-strain curves of UHS and HPC," Journal of Chongqing Jianzhu University, 2000.
[14] F. J. Guild, A. C. Taylor, and J. Downes, Composite Materials, John Wiley Sons, 2017.

[15] R. Talreja, "Matrix and fiber-matrix interface cracking in composite materials," Modeling Damage, Fatigue and Failure of Composite Materials, pp. 87-96, 2015.

[16] W. J. Yin Hongfeng, Composite Materials, Press of Metallurgy Industry, 2012.

[17] K. T. Faber and A. G. Evans, "Crack deflection processes-I. Theory," Acta Metallurgica, vol. 31, pp. 565-576, 1983.

[18] H. R. Pakravan, M. Latifi, and M. Jamshidi, "Hybrid short fiber reinforcement system in concrete: A review," Construction and Building Materials, vol. 142, pp. 280-294, 2017.

[19] B. H. Tekle, A. Khennane, and O. Kayali, "Bond of spliced GFRP reinforcement bars in alkali activated cement concrete," Engineering Structures, vol. 147, pp. 740-751, 2017.

[20] L. Yang, Z. Wu, D. Gao, and X. Liu, "Microscopic damage mechanisms of fibre reinforced composite laminates subjected to low velocity impact," Computational Materials Science, vol. 111, pp. 148-156, 2016.

[21] R. B. Jewell, K. C. Mahboub, T. L. Robl, and A. C. Bathke, "Interfacial bond between reinforcing fibers and calcium sulfoaluminate cements: fiber pullout characteristics," ACI Materials Journal, vol. 112, no. 1, pp. 39-48, 2015.

[22] A. Medeiros, X. Zhang, G. Ruiz, R. C. Yu, and M. D. S. L. Velasco, "Effect of the loading frequency on the compressive fatigue behavior of plain and fiber reinforced concrete," International Journal of Fatigue, pp. 342-350, 2015.

[23] J. Qiu, X.-N. Lim, and E.-H. Yang, "Fatigue-induced deterioration of the interface between micro-polyvinyl alcohol (PVA) fiber and cement matrix," Cement and Concrete Research, vol. 90, pp. 127-136, 2016.

[24] C. Q. Shen Rongxi, New type of fiber reinforced cement matrix composites, Press of China Building Industry, 2004.

[25] C. Carloni, D. A. Bournas, F. G. Carozzi et al., Fiber Reinforced Composites with Cementitious (Inorganic) Matrix, Springer Netherlands, 2016.

[26] J. Zhang, Z. Wang, Q. Wang, and Y. Gao, "Simulation and test of flexural performance of polyvinyl alcohol-steel hybrid fiber reinforced cementitious composite," Journal of Composite Materials, vol. 50, no. 30, pp. 4291-4305, 2016. 

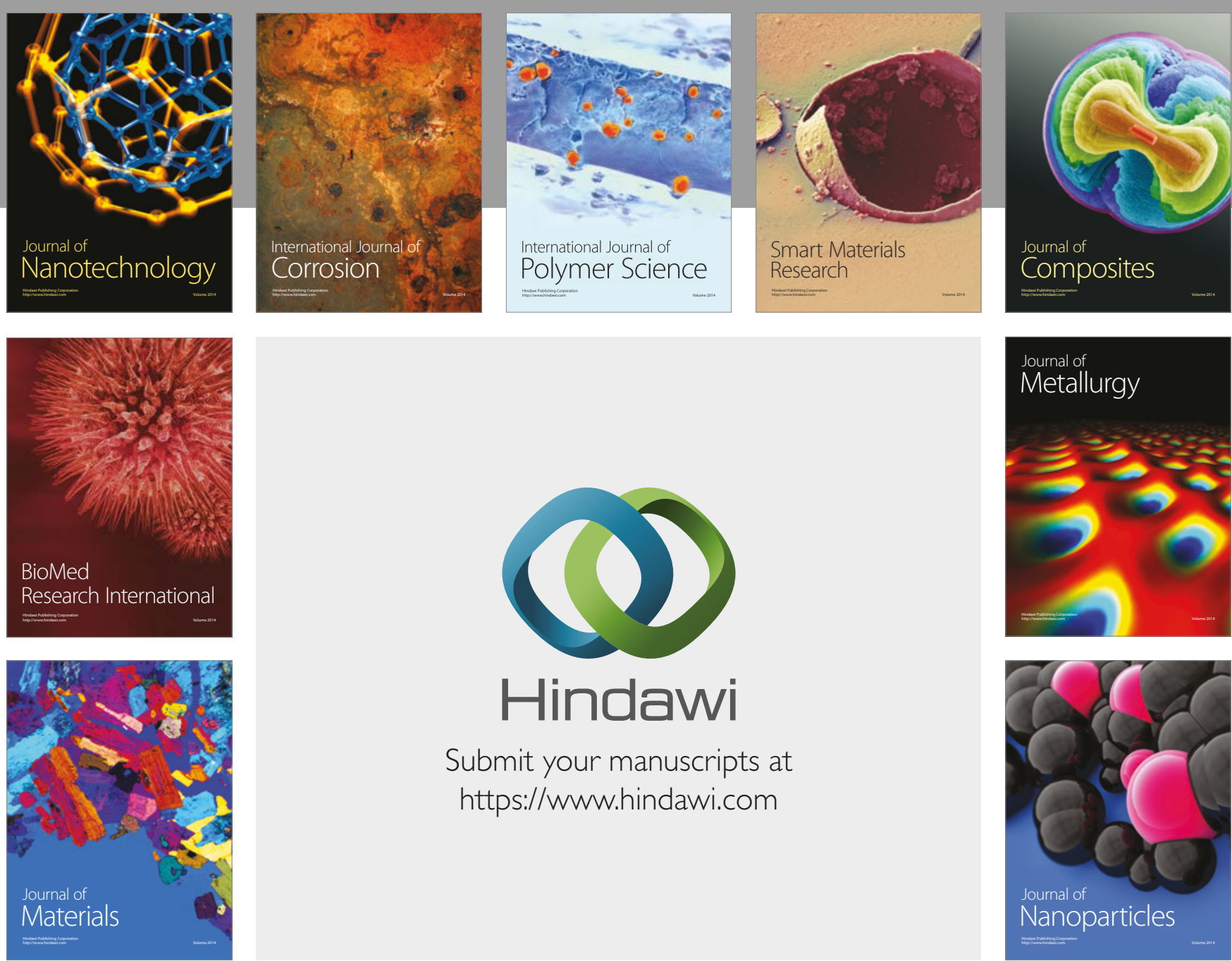

\section{Hindawi}

Submit your manuscripts at

https://www.hindawi.com
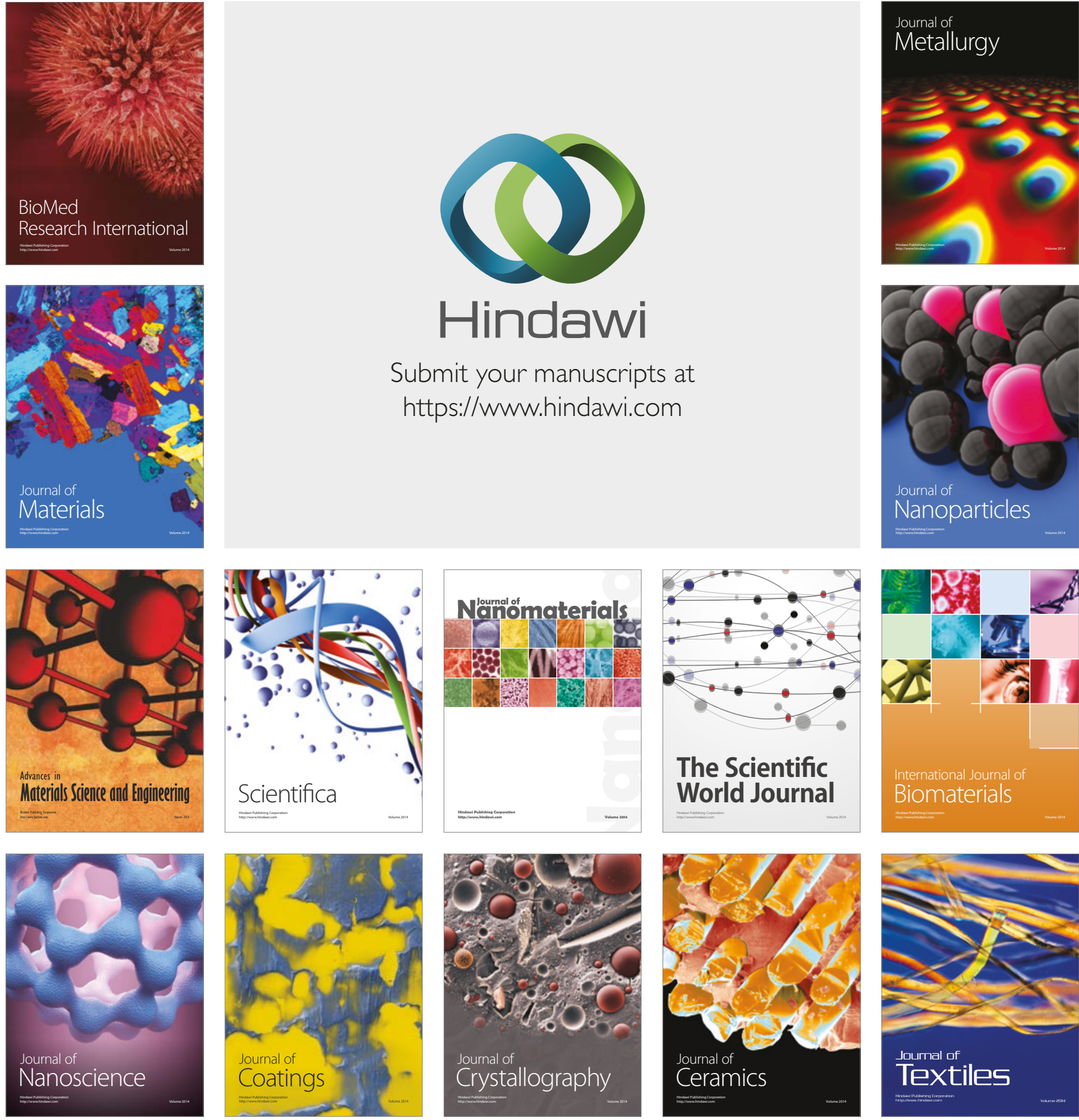

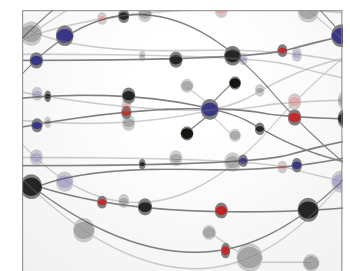

The Scientific World Journal
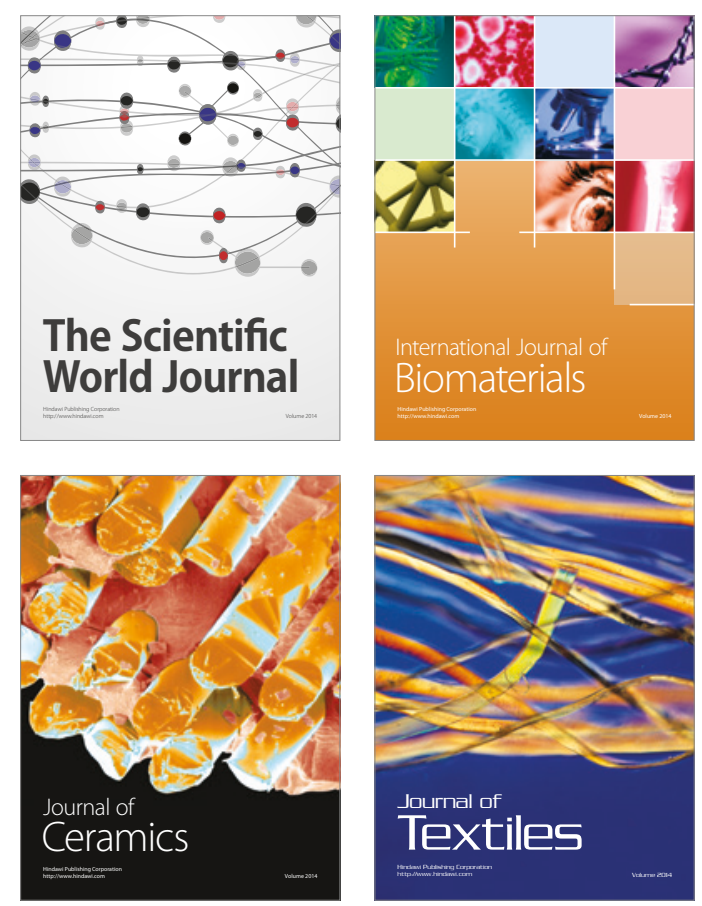